\title{
A Case Study Of Crisis Communication, Image Restoration And Utilitarian Ethics: A Recall Of Contaminated Peanut Butter Examined
}

Kylie D. Roman, Illinois State University, USA

Maria A. Moore, Illinois State University, USA

\begin{abstract}
In a publicized crisis, the goal to ethically and restoratively regain public trust is paramount to most corporations. In 2009, the food industry in the USA was thrust into a crisis when the Peanut Corporation of America (PCA), a small peanut processing company in Georgia, was linked to a salmonella outbreak resulting in illness, fatalities, and the recall of close to 4,000 products. Many large food product companies bore the economic impact, though they were not the cause of the problem. Consumers became confused about which products were safe. The oversight stewardship abilities of the Food \& Drug Administration (FDA) became suspect. PCA went bankrupt and its owners face federal prosecution. To fully understand the public communication decisions made by PCA, principles of Image Restoration Theory are used to examine and evaluate PCA's responses to this event. To render generalizable knowledge for others from this historic case, Utilitarian Ethics are applied to the actions of PCA, the FDA, and the peanut industry as a whole. This analysis of past events may serve to empower business leaders and corporate communicators faced with correcting future food borne illness problems and communicating with their key constituencies of regulators, business partners and consumers.
\end{abstract}

Keywords: Crisis Communication; Image Restoration Theory; Utilitarian Ethics; Business Ethics; Food Safety; Peanut Butter; Food Product Company; Salmonella; Business Case Study

\section{INTRODUCTION}

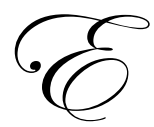

very day we consume foods that we trust are going to be safe to eat. The reliability of our nation's food supply depends upon a complex relationship among the state, the food industry and the public. Fundamentally we trust that companies are doing what they should to produce high quality products with high safety assurance. When harmful products reach the public, however, a crisis ensues that may lead to financial ruin or permanent damage to a company's reputation. How a company or industry responds to the crisis will ultimately determine its future (Siomkos \& Malliaris, 1992).

A food staple found in most American homes is peanut butter, accounting for $\$ 900$ million in retail sales annually. Parents regularly pack their children's lunches trusting that a peanut butter and jelly sandwich will be both a safe and healthy meal for their child, ("About the peanut industry," 2010). But in 2009, this trust was broken and that seemingly benign peanut butter and jelly sandwich became potentially fatal.

The 2009 peanut butter crisis led to the most costly food recall in history, causing about 200 companies to recall close to 4,000 products while costing food companies and the government more than $\$ 1$ billion (Flynn, 2009). This crisis occurred when a salmonella outbreak at the Peanut Corporation of American (PCA) plant in Blakely, Georgia lead to nine deaths, over 700 illnesses, and a list of recalled products from peanut butter to candy to even dog food (Guthrie, 2009). Though PCA has filed for bankruptcy protection, closed its operations, and fired its 
employees; there are 123 pending claims against the company's $\$ 12$ million product liability policy. A court trustee has recently decided to allow the money to be divided among the victims of the outbreak, to be distributed based upon injury severity (Flynn, 2010a).

No one could have imagined the impact possible from a crisis with peanuts. The consequences were felt not only by the guilty company, PCA, but also by the entire food industry. The outbreak affected not only tubs of peanut butter, but countless other foods using peanut paste as an ingredient. Huge companies using peanut ingredients processed by PCA such as The Kellogg Company as well as small companies like Aspen Hills Inc., suffered the recall consequences caused by one small and mostly invisible company handling less than $2 \%$ of the nation's peanuts (Wittenberg \& Dohlman, 2010). The producers of the nation's leading peanut butter brands, companies such as The J.M. Smucker Company (Jif), Unilever (Skippy) and ConAgra Foods (Peter Pan), were also among the companies who suffered serious financial outcomes of this terrible crisis though they had no recall issues with any of their products.

This case study will examine the crisis with an emphasis on its effects on the offending company-PCA, the Food and Drug Administration, and the entire peanut-based food industry. In order to understand the impact of the crisis on business strategies, the ethical philosophy of Utilitarianism will be discussed and applied. In addition, the process of image restoration, a central public relations theoretical typology, will be applied to both analyze the crisis and its communication strategies and as an ethical framework and perspective for any crisis situation.

\section{THE CRISIS}

After the first five deaths and more than 400 illnesses were linked to salmonella poisoning, PCA, the source of the contamination, issued a recall on January 13, 2009 for products it had made over the past six months. The company issued the recall after several residents in a nursing home were sickened from a container of King Nut brand peanut butter, manufactured by PCA, which was found to contain a strain of salmonella - a group of bacteria that can cause typhoid fever or a number of other illnesses, including food poisoning, gastroenteritis and enteric fever from contaminated food products ("Definition of salmonella," 2010). Further links to PCA extended to a recall of hundreds of consumer products made as far back as January 1, 2007. As the list widened to two years' worth of re-called products so did the number of deaths and illnesses, with a large majority being children and the elderly, totaling nine deaths and over 700 illnesses (Wittenberger \& Dohlman, 2010).

PCA was a small, family-owned and operated business headquartered in Lynchburg, Virginia (Weise \& Schmit, 2009). The company's factory in Blakely, Georgia, which is now closed, not only packed peanut butter but also produced a peanut paste used to make candy, crackers, and many other kinds of foods. The company's bulk peanut butter was shipped to many foodservice industries, private label food companies and institutions, including nursing homes, hospitals, and schools. While the tainted peanut butter was relatively easy to track and discover, the peanut butter paste was much harder to find. "Tracking how the paste travels through the food supply can be challenging, because several companies can be involved in making the final food" ("Peanut butter recall," 2009, para. 4). It was extremely difficult to find all of the possible distribution end points of the peanut paste. PCA supplied it to some of the largest food makers in the nation such as Kellogg's and General Mills for use in a variety of products. This outbreak "illustrated the complexities of the industrial food chain, and left consumers scrambling to figure out if some food in their cabinets posed a danger" ("Peanut butter recall," 2009, para. 2).

The business of selling peanut butter is worth nearly $\$ 900$ million a year (Severson, 2009). With a business this large, the negative effects of a major health crisis caused by this product had a profound ripple impact on the industry. As the crisis expanded, so did the number of companies pulling their products off of the shelves. While many big companies said they were not impacted, many still recalled products voluntarily. Authorities said that peanut butter sold in grocery stores was not affected, but consumers were still in doubt (Wittenberger \& Dohlman, 2009). Manufacturers of peanut butter and peanut products that were not affected, such as The J.M. Smucker Company and ConAgra Foods, had to react as well. These companies enhanced their communication strategies to reassure consumers that their products were safe (Lee, 2009). The J.M. Smucker Company, maker of Jif and Smucker's brands, added messaging to its websites and issued a news release to inform consumers that its products were not involved in the recall. ConAgra, distributor of the Peter Pan brand, also added information to its websites, 
to assure its consumers (Lee, 2009). As consumers became wary of the product, these companies with no relationship to the actual recall took a hard hit with drops in sales amid consumer confusion.

In February 2009, the New York Times reported that peanut butter sales were down by 25 percent. "The drop-off is so striking that brands like Jif are taking the unusual step of buying ads to tell shoppers that their products are not affected, and giving them a coupon to make sure they do not learn to live without a staple that almost every child loves - and more than a few of their parents, too" (Martin \& Robbins, 2009, para. 2). Companies in the peanut butter business had to quickly employ communication strategies to drive up sales.

Large food companies such as The J.M. Smucker Company, The Kellogg Company, General Mills and ConAgra Foods, were not the only ones troubled by the recall. Small businesses were also suffering immensely. The recall "opens a window not only onto the ubiquity of peanuts in food, but also into the complexity of the nation's food system. Without the resources of big companies, small businesses have a particularly hard time navigating that system." (Cook, 2009, para. 4). These small businesses had a continued disadvantage. While big companies have the experience and staff to handle a crisis like this, small businesses have never had to deal with a crisis this large (Cook, 2009).

Not only were consumer product companies hurting, but the one billion dollar peanut farming industry also suffered. As stated by senior vice president of the Grocery Manufacturers Association, Robert Brackett, "All it takes is a little company, and it has a huge ripple effect" (Schmitt \& Weise, 2009b, para. 4). As in past food scares consumers began to tire of checking recall lists and to shun anything with peanuts as an ingredient. With a recall as big as this, the negative impact on the industry was enormous and long lasting (Schmitt \& Weise, 2009a).

As uncertainty continued among consumers, the Food and Drug Administration (FDA) escalated their investigation into the problem. The FDA's inspection report revealed "poor sanitation, conditions that would allow salmonella to spread, a gap in the roof through which salmonella-contaminated water or bird feces could fall, the presence of roaches and failure by the firm to check that its peanut-roasting process killed salmonella" (Schmitt \& Weise, 2009a, para. 10). In addition to poor factory conditions, working conditions were also poor. The federal inspection concluded, "the plant should never have been allowed to make peanut butter at all because it did not adequately separate raw and finished products" (Harris, 2009, para. 21). With this inspection, the FDA announced a criminal investigation into the actions of the PCA. Federal health officials claimed that PCA knowingly sold contaminated peanut butter and peanut products to major food makers (Harris, 2009). Stephen Sundlof, director of the FDA's Center for Food Safety and Applied Nutrition states, "Foods are supposed to be produced under conditions which will not render them injurious to health" (Gallagher, 2009, p. 1).

The FDA found that over two years, the company had identified salmonella over a dozen times during its own testing program. After retesting the product in a separate laboratory, PCA decided to release the products knowing there was a chance of salmonella contamination. Since PCA failed to disclose this information to authorities, both legal and ethical dilemmas became obvious. Congresswomen Rosa DeLaura stated, "The actions by the Peanut Corporation of America can only be described as reprehensible and criminal. Not only did this company knowingly sell tainted products, it shopped for a laboratory that would provide the acceptable results they were seeking." Congressmen Henry Waxman stated, "They seem to be a company more concerned with its bottom line than the safety of its customers" (Gallagher, 2009, p. 1).

With this crisis affecting not just one industry, but many others as well, there may be regulatory changes initiated worldwide to restore public confidence (Smith, 2009). In the past, guidelines have been voluntary. "What they're banking on is that everybody in the industry is going to do the right thing, and unfortunately, if the Peanut Corporation of America has taught us nothing else, it's that not everyone is going to do the right thing" (Weise, 2009 , p.1B). This salmonella outbreak has put the entire food industry on notice that it must ensure not only the safety of the food it products, but the ingredients it buys as well (Weise, 2009).

Since the January 2009 recall and criminal investigation, PCA has gone bankrupt and all corporate operations have been ceased. Criminal and civil court proceedings await and are, as of this writing, unresolved as described in several documents by Flynn (2009, 2010a, and 2010b). But as demonstrated, this crisis had profound 
impact not only on PCA, but also the entire food industry. One small company had the ability to impact giant corporations and general public health. It is not the first disruption of our food-chain safety net, and it has not been the last as subsequent recalls of spinach and alfalfa sprouts replaced peanut butter in the headlines ("Recalls \& alerts," 2010).

As food-producing companies may face future crises of food contamination with the resulting need to both restore their image and communicate with key constituencies, it becomes of key importance to analyze this case to determine what went right and wrong to empower others faced with a similar crisis. The communication strategies taken by PCA will be examined to determine how they attempted to restore their image through an analysis using image restoration theory. The business strategies of PCA, the FDA, PCA-client companies, and others in the peanut industry will be examined through a lens of utilitarian ethics.

\section{METHOD}

The purpose of this case study is to summarize the actions and corporate communications emanating from PCA in its attempt to restore its reputation and to control the framing of the story as the salmonella crisis began, expanded, and concluded with the company's demise. Additionally, the actions of others (the FDA, companies using PCA products, and companies in the same industry without tainted products) were analyzed for efficacy using utilitarian ethics.

Original artifacts produced and distributed by various organizations during the crisis were examined. PCA's responses were created for and distributed through their website. Each official PCA news release was examined. Contemporaneous news reports from national media were examined. The official reports on this incident from the US Department of Agriculture, the FDA, Congressional Hearings, and the Center for Disease Control were examined (Wittenberger \& Dohlman, 2010; "Peanut products recall," 2010; United States Congress; \& "Center for," 2008). The official statements and crisis marketing strategies of the three main peanut butter brands in the USA-J.M. Smucker Company (Jif), Unilever (Skippy), and ConAgra (Peter Pan)—were examined ("Important update," 2009; "A message to," 2009; \& "Peter Pan safe," 2009). The following two primary research questions guided this inquiry and analysis:

Question 1: $\quad$ Through the lens of Image Restoration Theory, what were the strategic corporate communication decisions made and implemented by PCA?

Question 2: $\quad$ Through the paradigm of Utilitarian Ethics, what were the strategic business responses of PCA, the FDA, other corporations using PCA products, and corporations in the peanut business sector but not customers of PCA?

\section{IMAGE RESTORATION THEORY}

Image restoration discourse-a dominant paradigm for analysis of crisis communication-is a viable approach for developing and understanding messages that respond to corporate image crises. The constructs of this theory can also be very useful as an ethical framework for a crisis, both prospectively as an ethical guideline and retrospectively as a responsive strategy. Benoit (1997) argues that image restoration discourse focuses on message options. It asks the question "what can a corporation say when faced with a crisis?" (Benoit, 1997, p. 178). This argument can be taken further to suggest that in a crisis situation certain message strategies can be utilized to ensure the most ethical responses for the public affected by the crisis.

Benoit (1997) offers a typology of five broad categories of image restoration strategies that respond to threats of image in a crisis situation including, denial, evasion of responsibility, reduce offensiveness, corrective action, and mortification. Benoit and Brinson (1994) describe image as "the perceptions of the source held by the audience, shaped by the words and acts of the source" (p. 75). They further explain that statements of other actors to the audience can influence one's image as well. These perceptions are determined by those individuals that are salient to the source at the time, which can include a variety of publics (Benoit \& Brinson, 1994). As corporations face threats to their reputations they often resort to image restoration discourse (Benoit \& Brinson, 1994). 
Ulmer, Seeger, and Sellnow (2007) explain "in essence, image restoration and its variants attend to questions of reputational repair by articulating the range of assorted strategic messages likely to repair the image of the organization or individual under attack" (p. 130). The other affected companies in the industry that are also experiencing the consequences of the crisis can utilize these strategies to maintain their legitimacy. Sellnow, Ulmer, and Snider (1998) state, "if organizations are to recover from crises, they must regain or maintain their social legitimacy" (p. 62). To be viewed as socially legitimate, organizations must continue to argue that they are functioning in a manner that is consistent with society's expectations (Sellnow et al., 1998). Thus, the typology of image restoration strategies can be a tool for companies to reestablish this social legitimacy.

\section{Denial}

The first approach to image repair is denial, in which "the accused either simply repudiates the accusation or shifts the blame elsewhere" (Benoit \& Brinson, 1994, p. 77). A corporation can "deny that the act occurred, that the firm performed the act, or that the act was harmful to anyone" (Benoit, 1997, p. 179). A corporation can also choose to shift the blame, in which they argue that another person or organization is actually responsible for the act (Benoit, 1997).

\section{Evasion of Responsibility}

Evasion of responsibility is a second approach, which broadly defined, occurs when the accused does not deny committing the offense, but rather claims a lack of responsibility (Benoit \& Brinson, 1994). This lack of responsibility can take on four forms. A provocation strategy would exist when a corporation says its act was a response to another's offensive act, and that the behavior can be seen as a reasonable reaction to that provocation. A corporation can also evade responsibility by utilizing defeasibility. In this form, a corporation says its act was because of a lack of information about or control over important elements of the situation. A third form is to claim that the action occurring was an accident. Benoit \& Brinson (1994) argue that "if a company can convince the audience that the act in question happened accidentally, it should be held less accountable, and the damage to that business's image should be reduced" (p. 180). The fourth option is for the company to claim that the offensive act was performed with good intentions, meaning that the corporation meant well by its actions (Benoit \& Brinson, 1994; Benoit, 1997).

\section{Reduce Offensiveness}

The third approach is to reduce offensiveness. In this form, the company strives to reduce the perceived offensiveness of the act, and hence the damage to the accused image (Benoit \& Brinson, 1994). This strategy takes on six forms. First, a company may use bolstering to "strengthen the audience's positive feelings toward itself, in order to offset the negative feelings connected with the wrongful act" (Benoit, 1997, p. 180). For example, a company may describe some of its positive characteristics or some of the positive acts that it has done in the past in an attempt to bolster its image and offset damage to its reputation (Benoit, 1997). Second, a company may use minimization to try to minimize or downplay the negative feelings associated with the wrongful doing (Benoit, 1997). Third, a company can utilize differentiation, in which "the act is distinguished from other similar but more offensive actions (Benoit, 1997, p. 181). Fourth, a company can employ transcendence, in which a company attempts to place the act in a more favorable context. Fifth, a company may attack the accuser by forming messages that reduce the credibility of the accuser. The sixth and final form is compensation. In this form, a company would reimburse the victim(s) for the wrongdoing (Benoit, 1997).

\section{Corrective Action}

A fourth strategy for image restoration is corrective action, in which "the company promises to correct the problem" (Benoit, 1997, p. 181). Utilizing this method, a company can take the form of "restoring the state of affairs existing before the offensive action, and/or promising to prevent the recurrence of the offensive act" (Benoit, 1997, p. 181). A company works to correct the problem by discussing a plan to fix it as well as prevent it in the future. 


\section{Mortification}

The fifth and final general strategy for image restoration is mortification. In this case, a company apologizes for the wrongdoing and asks forgiveness (Benoit, 1997). This must be used carefully as a potential drawback is that it might invite lawsuits from victims.

These five strategies have shown to be useful in forming messages in a response in a crisis event. As previously stated, these strategies also have ethical implications. A continuum exists in which these strategies lie, ranging from most ethical to most unethical. This ethical continuum can be considered in tandem with image restoration when an organization faces ethical dilemmas in a crisis situation and during their image repair campaigns. While context and situation definitely play a part in their existence on the continuum, for the most part they take the form shown in figure 1.

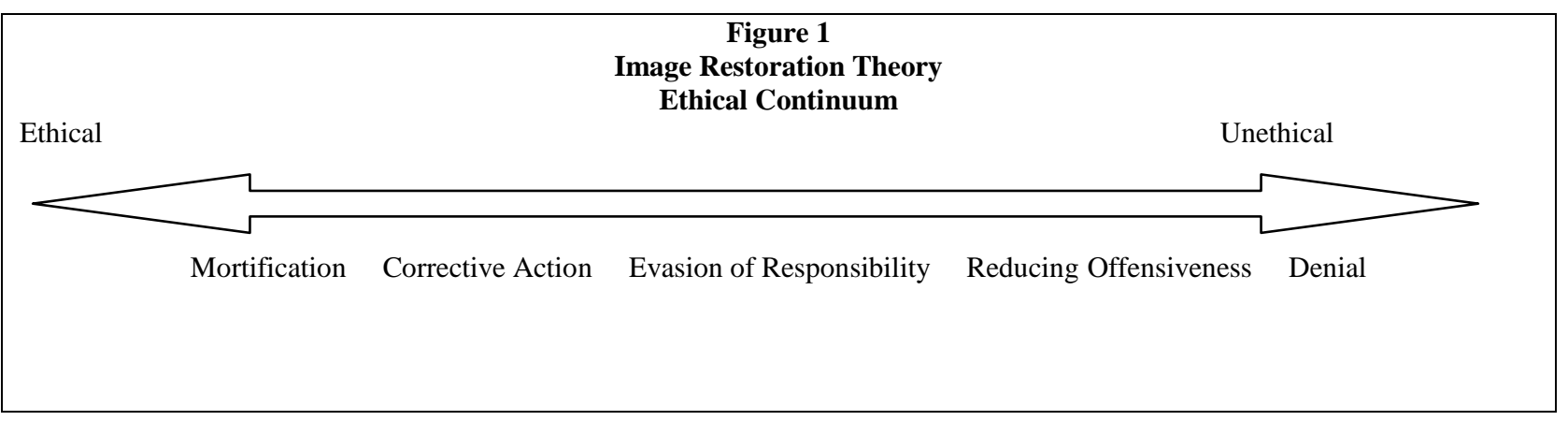

\section{IMAGE RESTORATION THEORY DATA ANALYSIS OF PCA MESSAGES}

After a media audit of relevant data, and careful analysis of PCA's message strategies, particularly from Stewart Parnell, owner and president of PCA, image restoration theory can be applied systematically. In an attempt to repair its image, the company demonstrated multiple message strategies during its image repair campaign over a two month time period. These messages will be placed on the previously argued ethical continuum of image restoration typologies.

In the first phase of PCA's image restoration campaign, the company announced a voluntary recall for peanut butter produced in its processing facility because it had the "potential to be contaminated with salmonella." Parnell stated, "We deeply regret that this has happened. Out of an abundance of caution, we are voluntarily withdrawing this product and contacting our customers. We are taking these actions with the safety of our consumers as our first priority" (PCA, 2009a, para. 5). According to Benoit's typology, this message can be categorized as corrective action. While this recall was "voluntary," it can be argued that they clearly recalled the products because the enormous amount of pressure and the investigation into the company. While this corrective action can be placed as more ethical on the continuum (See figure 1), the company clearly knew that there was a big chance that salmonella could have infected its products, which makes it a much more unethical act. Corrective action was utilized as more of a preventative strategy early on in its public communication.

As the recall widened and began to include more and more products connected to PCA, its messages also changed. Parnell stated, "We deeply regret that this product recall has expanded, and our first priority is to protect the health of our customers" (PCA, 2009b, para. 8). Further messages included "We have been devastated by this, and we have been working around the clock with the FDA to ensure any potentially unsafe products are removed from the market" (PCA, 2009c, para. 8). In analyzing these messages, it is interesting that Parnell never actually apologized. According to the typology, this message was implemented to reduce the offensiveness of the event, more specifically, bolstering. For instance, Parnell attempts to reduce the offensiveness by stating that their priority is protecting the health of consumers and that they are working with the FDA to ensure that the products are 
removed. Clearly, he is trying to stress the good things that the company is doing, in an attempt to diminish the actual wrongdoings. It can be argued that the ethicality of these messages is low because Parnell is attempting to bolster its image.

As the criminal investigation began, PCA's message strategies changed in an attempt to repair its image. In a particular January 28, 2009 press release, PCA utilized multiple messages. PCA and the Parnell Family stated, "the goal of PCA over the past 33 years has always been to follow the U.S. Food and Drug Administration's good manufacturing practices in order to provide a safe product for consumers" (PCA, 2009d, para. 1). Here again, we see bolstering in an attempt to show the positive traits of the company, questioning the ethicality of the message. After these messages, Parnell argued that PCA did not agree with all of the FDA's observations about the facilities poor conditions, and there were some inaccuracies with the reports (PCS, 2009d). Here we see some shifting of the blame. PCA is arguing that the FDA's reports were not correct in an attempt to restore its negative image, again falling short of ethical guidelines. Finally, in this same press release we hear an apology for the first time. Parnell stated:

To any consumers affected by these issues, to the food industry and to peanut consumers everywhere, we are sorry our process fell short of not only our goals, but more importantly, your expectations. We understand the seriousness of the situation that our company faces with the current product recall crisis and we deeply regret that these circumstances are causing distress to our consumers, our customers and our employees. (PCA, 2009d, para. 6)

Here, mortification is finally utilized by apologizing for the act. In addition, Parnell apologizes to not only those consumers affected, but also the entire industry that was damaged from the crisis. While this is considered ethical on the continuum, PCA should have utilized this strategy much sooner.

As the criminal investigation went on, PCA continued to utilize mortification as a message strategy. Parnell continued to express his "deepest and most sincere empathy for those sickened in the salmonella outbreak and their families" (PCA, 2009e, para. 1). In addition, he emphasized that there had been a great deal of confusion and misleading information in the media. Parnell stated:

We want the public to know that there were regular visits and inspections of the Blakely facility by federal and state regulators in 2008. Independent audit and food safety firms also conducted customary unannounced inspections of the Blakely facility in 2008. One gave the plant an overall superior rating, and the other rated the plant as Meet or Exceeds audit expectations (Acceptable- Excellent) ratings. (PCA, 2009f, para. 2)

This message demonstrates PCA's use of denial. They are denying the claims made about lack of inspections and the claims about the poor ratings. Furthermore, Parnell shifts some of the blame in an attempt to argue that PCA is not the only one responsible for the act. This strategy continues to show that the FDA also needed to take responsibility.

In a final press release on February 20, 2009, PCA announced its bankruptcy and directed all further information to the FDA Website (PCA, 2009h). This final press release did not include any type of image restoration strategies. It can be assumed that since the company was already going under and bankrupt, that all attempts to repairs its image ceased. All prior attempts to repair PCA's image were not effective, and in the end this crisis was much too large to be permanently restored.

\section{UTILITARIAN BUSINESS ETHICS}

\section{Defining Ethics}

In general terms, ethics can be described as a type of philosophy questioning what is right and wrong, along with what is good and bad. Ethical dilemmas can range from small personal predicaments to dilemmas that can affect millions of people, such as the peanut butter recall. McElreath (1996) states "by definition, ethical dilemmas are not easy; they are perplexing situations involving decisions about what is right and wrong...They always have something to do with values, which means they evoke strong emotions" (McElreath, 1996, p. 320). In any ethical 
dilemma or crisis situation, there is a potential for someone or something to be hurt. In this case, those who suffered death and illness incurred grave harm; as well as the devastating financial impact on the entire food industry.

In discussing ethics, the idea of morals also becomes a paramount importance. There are some distinctions that can be made between the two. On one hand, "ethics can be defined narrowly as standards of personal integrity and honest dealings, especially between individuals within organizational settings" (McElreath, 1996, p. 321). On the other hand, morals can refer to "principles considered important for acceptable behavior by individuals within families, communities and society at large" (McElreath, 1996, p. 321). There is also a distinction between ethicality and legality, clearly demonstrated in the peanut butter recall crisis discussed. In some situations these two concepts can become contradictory. In a particular crisis, what is ethical may or may not be legal or visa versa. This becomes of importance in discussing a crisis that is breaking both ethical and legal codes. Ethics frames the practice of corporate communication and public relations and thus can be a compass for understanding and guiding a crisis situation.

A definition of business ethics is not completely distinct from individual ethics. Business ethics can be seen as a system of ethical principles applied to a commercial business or organizational environment. While some firms assume that ethical business practices will add cost or inefficiency, in practice business ethics can add value for customers and result in both increased profitability and performance (McMurrian \& Matulich, 2006). Business ethics provide guidelines for recommended behavior by organizations in both their strategy formulation and day-today operations ("Business definition," 2010). It can also be argued that businesses cannot operate in a one-size-fitsall approach, but that the ethical decisions made in a crisis will impact the image of business well into the future (Budden \& Budden, 2010).

\section{Utilitarianism}

An ethical theory applicable to analyzing the peanut butter recall crisis is John Stuart Mill's theory of utilitarianism. It is a teleological ethical theory and is a much-used foundation for capitalistic business ethics (Mill, 2002). Teleological ethical principles and systems stress the idea of the end result of an action rather than the action itself (Day, Dong, \& Robins, 2001). This level of philosophy emphasizes outcomes. At its most basic form, the ends justify the means. In this approach, ethical actions are those that result in the greatest good. This naturalistic approach focuses on the causes and consequences of actions and is situationally specific (McElreath, 1996). McElreath (1996) states, "it does not assume a single source of authority, but rather emphasizes factors leading up to and following a specific action" (p. 322). Teleology can be looked at in restricted and universal forms. Restricted forms calculate the consequences only for a particular person or group while universal teleology stresses consequences to society as a whole. Also known as utilitarianism, universal forms stress the greatest good for the greatest number (Curtin \& Boynton, 2001).

Curtin and Boynton (2001) discuss that critics of teleology suggest that "knowing the consequences of actions before the fact can be difficult, that not all things can be assigned a numerical value, and that looking only at short term consequences can be shortsighted" (p. 412). Although this may be true in looking at a crisis after the fact, teleological ethics can be utilized in an attempt to "fix" the aftermath of a crisis through its communication strategies and, in this case, the influence of the crisis on the food industry. Teleological ethics, particularly utilitarianism, could be utilized both prospectively and retrospectively in any crisis situation.

Categorized as a classical theory and ethical philosophy, utilitarianism stresses consequences to society as a whole. This ethical framework socializes the individual to think and act ethically, and provides a moral framework for decision-making, while calling to seek the greatest happiness for the greatest number. In many crisis situations, utilitarian ethics can be utilized as a standard in decision-making to meet the needs of the greatest number of people in society.

In utilitarian ethics, "actions per se are not moral or immoral" (Pratt, 1993, p. 228). Instead, morality is dependent on the effects of publics. While resolving ethical issues according to their consequences on people, utilitarianism can be categorized into two basic forms. The first form, act utilitarianism, provides the most good for the greatest number. It justifies the morality of an action or crisis by its relevance to utility. The second form, rule utilitarianism, asks the question: when followed, what rule or moral principle will maximize the good (Pratt, 1993). 
In applying utilitarian principles to business ethics, a cost-benefit analysis is often used. Companies attempt to assess the strategic business costs before taking action that should result in ideal profitable consequences favorable to all constituencies. The company makes a profit while the consumer benefits from their product. In a utilitarian model products are safe and give value for money. Ethical business practice, using utilitarianism, would thus consider the good and bad consequences for all, treat all constituents as having equal rights, and would use it as an objective, quantitative way to make a moral decision (Lundy, 2009). When utilitarian analysis indicates that a particular action taken does indeed benefit the greatest amount of people in a particular crisis situation, Utilitarians would argue that an ethical decision was made.

\section{APPLIED UTILITARIAN ETHICS TO PCA, FDA, \& PEANUT INDUSTRY ACTIONS}

Utilitarianism, as well as universal teleology, stresses the consequences to society as a whole, so it is clear that there were many consequences to the publics impacted by the 2009 peanut butter recall. There were a variety of publics that were being hurt from this crisis, both physically and financially. With the deaths and hundreds of illnesses among consumers, and the vast amount of companies in the food industry financially affected, this recall clearly took a toll on commerce and society. Because of the large number of people and companies impacted, utilitarianism can be examined from multiple perspectives. Do the ends justify the mean? Did the greatest good occur for the greatest number of people?

\section{Utilitarian Ethics of the Peanut Corporation of America (PCA)}

As stated, from a utilitarian framework, the ends must justify the means. From PCA's perspective, while their poor working and facility conditions may have had a positive impact on short-term profit, the strategy was far from ethical as is evidenced by the end result. In the end, these poor business practices backfired on them. Having poor working conditions and an unsanitary facility resulted in anything but the greater good. While knowing the consequences of actions before the fact can be difficult, it was common sense to anyone conducting a simple utilitarian-based cost/benefit or risk/reward analysis that these conditions could end in disaster. This utilitarian perspective has implications for the aftermath of the crisis itself. Thus, the ends did not justify the means. In addition, lying to its publics, particularly the FDA and the companies that they supplied to, about the safety of its products, is a not an ethical act and does not benefit any of PCA's constituent publics in any manner.

As utilitarianism stresses the greatest good for the greatest number of people, the actions taken by PCA can be further defined as unethical. With the peanut butter industry amounting to a $\$ 900$ million business, it is clear that a strategy serving the greatest number of people would not focus on the needs of the small, family-owned company that caused this terrible crisis. While in the short-term it may have been saving them money and time doing things the "wrong" way, in the end it would have been much more effective to strategize for the greater good in their initial operations. In this crisis, the benefits did not outweigh the costs. For example, the costs of people's lives, illnesses, as well as the financial downfall, are not equivalent to the short-term company profit gained by these questionable practices. Furthermore, not only did the recall crisis hurt companies financially, but it also took away the trust that loyal consumers had with particular brands. It is important to recognize how a crisis in a small company can ripple through a huge industry. PCA should have realized the potential negative impact their poor safety strategies could have for many customers and client companies. It would have been sound utilitarian ethics as well as sound business practice.

PCA suffered terminal consequences for their unethical decisions. The company is bankrupt. All employees lost their jobs. The bankruptcy court is addressing the claims of 123 victims. And PCA's owner, Stewart Parnell, may face federal criminal prosecution for felony violation of the Federal Food, Drug and Cosmetic Act for intent to defraud customers.

\section{Utilitarian Ethics of the Food \& Drug Administration (FDA)}

The FDA should have utilized a utilitarian framework as well. Because these facilities were not checked on a regular basis, the results did not maximize the good. The FDA serves the public interest and uses its resources as the public's representative to ensure food safety. The FDA practices of irregular and ineffective monitoring of PCA 
led again to the ends not justifying the means. Much of the resulting blame has been put on the FDA because this is not the first time something like this has happened and further food safety issues continued to occur after this particular crisis. This had negative effects on the FDA and the current administration has indicated that change will occur so that higher standards will preclude a similar disastrous result.

\section{Utilitarian Ethics of the Peanut Industry}

Conversely to the unethical behavior from PCA and the FDA, other companies that purchased peanut butter or peanut paste from PCA, such as The Kellogg Company and General Mills, voluntarily pulled their products from shelves. Although they were not completely sure that their products were affected, they thought it was the right thing to do so that more people would not be sickened. Even though it hurt them financially, they decided that this would benefit the largest amount of people in the long run. It can be argued that corporations should keep tabs on their suppliers, such as those that purchased from PCA. A utilitarian cost-benefit analysis would have been effective for the companies who did purchase from them. Furthermore, some large food industries companies, such as The Kellogg Company have begun to hire private inspectors to check out plants so that something like this does not happen again. A utilitarian analysis would suggest these are positive ethical strategies.

Other companies who did not purchase products from PCA, such as The J.M. Smucker Company, and Unilever, also had to react. Even though their products had nothing to do with the recall they still felt that it would benefit the greatest amount of people to keep communications going throughout the crisis. They implemented public communication strategies to keep their consumers up to date with the information they had and let them know that they were not involved. They also found it effective and ethical to respect their loyal consumers and let them know that they could trust their products. These companies also employed positive ethical strategies and eventually enjoyed the positive consequences of a trusting, stable relationship with consumers. Their actions reveal that the business ethics principles of Utilitarianism can be an effective decision-making framework in any crisis situation.

\section{CONCLUSION}

As demonstrated, the crisis surrounding the 2009 peanut butter recall had a huge affect on many constituencies: the offending company-PCA, individuals sickened or killed by salmonella tainted food, the federal regulatory agency - the FDA, companies using PCA peanut products, and companies sharing the peanut butter sector without any connection to PCA. By analyzing the message strategies utilized by PCA, it is clear that there was a strategic and clear attempt to restore the company's image. An attempt that inevitably failed due to the unethical cost cutting and safety-violating operational strategies employed by the company.

Additionally, all constituents involved in this crisis displayed decisions and communications that revealed the many ethical dilemmas they faced. By understanding these dilemmas and evaluating the results based upon utilitarian ethics we better understand what happened in this case of the largest food recalls in history. Others can utilize this analysis of historical actions in determining how to react to future crises. Furthermore, this case reveals implications for constructing messages in an attempt to repair image. This case study argues that image restoration theory could also be utilized as an ethical framework. As demonstrated, this typology has implications for practitioners who are constructing messages in an image restoration campaign. While its message strategies did not show to be effective in this crisis, this case can provide an example for future cases that have ethical dilemmas, particularly ones that are impacting a large variety of publics.

As clearly shown, the food industry suffered profound consequences from the mistakes of one small business. Companies must be aware of the consequences of their decisions and strategies, as they are responsible for much more than themselves. One slip-up or compromised standard in a small factory has endless repercussions for the others involved. The spreading of the peanut butter recall is one that will have lasting impact because of the many people and companies impacted physically and financially. This case, viewed through the double lenses of image restoration and utilitarian ethics, provides new insights into image repair campaigns. 


\section{AUTHOR INFORMATION}

Kylie D. Roman (MS in Communication) is a corporate communications / public relations professional who resides in Akron, Ohio. She received her undergraduate degree from Ohio University and her master's degree from Illinois State University. E-mail: roman.kylie@gmail.com.

Maria A. Moore (Ed.D. in Education from National Louis University Chicago) is an assistant professor of Law and Ethics at the School of Communication, Illinois State University. She is an Emmy award winning documentary writer/producer and author of articles on media whistleblowing, learning communities, multimedia collaboration and business ethics. E-mail: drmariamoore@gmail.com. Corresponding author.

\section{REFERENCES}

1. A message to our customers. (2009, January 19). Retrieved June 25, 2010 from http://www.jif.com/aboutjif/peanut butter.asp.

2. About the peanut industry. (n.d.). Retrieved March 21, 2010, from http://www.peanutsusa.com/USA/index.cfm? fuseaction=home.page $\&$ pid=12.

3. Benoit, W. L. (1995). Accounts, excuses, and apologies: A theory of image restoration strategies. Albany: State University of New York Press.

4. Benoit, W. L. (1997). Image repair discourse and crisis communication. Public Relations Review, 23(2), 177-186.

5. Benoit, W. L. \& Brinson, S. L. (1994). AT\&T: Apologies are not enough. Communication Quarterly, 42, 75-88.

6. $\quad$ Business definition for business ethics. (n.d.). Retrieved June 25, 2010, from http://dictionary.bnet.com/definition/Business+Ethics.html.

7. Budden, C.B., \& Budden, M.C. (2010). Developing crisis management skills through a realistic case scenario. Journal of Business Case Studies (JBCS), North America, 4 (8), 2010. Retrieved April 25, 2011 from http://journals.cluteonline.com/index.php/JBCS/article/view/268/258.

8. Center for Disease Control. (2008, November 25). Multistate outbreak of salmonella infections associated with peanut butter and peanut butter-containing products-United States, 2008-2009. Retrieved from http://www.cdc.gov/mmwr/preview/mmwrhtml/mm58e0129a1.htm.

9. Cook, K. (2009, February 26). Peanut recall's ripples feel like a tidal wave for some companies. The New York Times. Retrieved September 20, 2009, from http://www.nytimes.com.

10. Curtin, P. A., \& Boynton, L. A. (2001). Ethics in public relations: Theory and practice. In R. L. Heath (Ed.), Handbook of public relations (p. 411-422). Thousand Oaks, CA: Sage.

11. Day, K. P., Dong, Q., \& Robins, C. (2001). An overview and discussion of issues for the $21^{\text {st }}$ century. In Heath, R.L. (Eds.), Handbook of public relations (pp. 403-410). Thousand Oaks, CA: Sage.

12. Definition of salmonella. (n.d.). Retrieved June 26, 2010, from http://www.medterms.com/script/main/art.asp?articlekey=6310.

13. Flynn, D. (2009, December 28). Top ten food safety news stories of 2009. Retrieved March 21, 2010, from http://www.foodsafetynews.com/2009/12/top-ten-food-safety-news-stories-of-2009/.

14. Flynn, D. (2010, February 2). PCA victims soon will see some money. Retrieved March 21, 2010, from http://www.foodsafetynews.com/2010/02/pca-victims-soon-will-see-some-money/.

15. Flynn, D. (2010, March 20). PCA owner hires criminal defense attorney. Retrieved March 21, 2010, from http://www.foodsafetynews.com/2010/03/pcas-parnell-hires-federal-criminal-defense-attorney/.

16. Gallagher, J. (2009, February 2). Congresswoman calls for PCA investigation. Supermarket News, p. 1.

17. Guthrie, P. S. (2009). Salmonella outbreak prompts demands for more scrutiny of food processing plants. Canadian Medical Association Journal, 180(10), E32-E33.

18. Harris, G. (2009, January 31). Peanut plant recall leads to criminal investigation. The New York Times. Retrieved September 20, 2009, from http://www.nytimes.com.

19. Important update on peanut situation (2009, February 17). Retrieved June 25, 2010 from http://www.unileverusa.com/mediacenter/pressreleases/2009/important-update-on-peanut-situation.aspx.

20. Lee, J. (2009, January 26). Salmonella scare spurs a boost in online research. PR Week, p. 1. 
21. Lundy, A. (2009). Applying utilitarianism to business ethics: the Ford pinto case. Retrieved June 25, 2010, from http://bizcovering.com/major-companies/applying-utilitarianism-to-business-ethics-the-ford-pintocase/.

22. Martin, A. \& Robbins, L. (2009, February, 7). Fallout widens as buyers shun peanut butter. The New York Times. Retrieved September 20, 2009, from http://www.nytimes.com

23. McElreath, M. P. (1996). Managing systematic and ethical public relations campaigns $\left(2^{\text {nd }}\right.$ ed.). New York: McGraw-Hill.

24. McMurrian, R. C. \& Matulich, E. (2006). Building customer value and profitability with business ethics. Journal of Business \& Economic Research (JBER), 4(11) (2006). Retrieved April 24, 2011, from http://journals.cluteonline.com/index.php/JBER/article/view/2710/2756.

25. Mill, J. S. (2002). The basic writings of John Stuart Mill (2002 Modern Library pbk ed.). New York: Modern Library.

26. Moss, M. (2009, February 9). Peanut case shows holes in safety net. The New York Times. Retrieved September 20, 2009, from http://www.nytimes.com

27. PCA (2009a, January 13). Peanut Corporation of America announces voluntary nationwide recall of peanut butter [Press release]. Retrieved from http://www.peanutcorp.com

28. PCA (2009b, January 18). Peanut Corporation of America expands nationwide recall of peanut butter [Press release]. Retrieved from http://www.peanutcorp.com

29. PCA (2009c, January 28). Peanut Corporation of America expands nationwide recall of peanut products: PCA announces the voluntary recall of all peanuts and peanut products Shipped from Georgia Plant [Press release]. Retrieved from http://www.peanutcorp.com

30. PCA (2009d, January 28). Statement by the Parnell family and Peanut Corporation of America (PCA) [Press release]. Retrieved from http://www.peanutcorp.com

31. PCA (2009e, January 31). Statement by Peanut Corporation of America (PCA) [Press release]. Retrieved from http://www.peanutcorp.com

32. PCA (2009f, February 4). Statement of Peanut Corporation of America (PCA) [Press release]. Retrieved from http://www.peanutcorp.com

33. PCA (2009g, February 8). Peanut Corporation of America provides additional information about expanded nationwide recall of peanut products [Press release]. Retrieved from http://www.peanutcorp.com

34. PCA (2009h, February 20). Peanut Corporation of America provides further information regarding recalled products [Press release]. Retrieved from http://www.peanutcorp.com

35. Peanut butter recall. (2009). The New York Times. Retrieved September 20, 2009, from http://topics.nytimes.com/topics/reference/timestopics/subjects/f/food_safety/peanut_butter_recall_2009/in dex.html

36. Peanut products recall (2009, March 23) Retrieved June 25, 2010 from http://www.fda.gov/Safety/Recalls/MajorProductRecalls/Peanut/default.htm

37. Peter Pan safe to enjoy; ConAgra Foods reaffirms none of its products involved in peanut butter salmonella investigation, (2009, January 28). Retrieved June 25, 2010 from

http://media.conagrafoods.com/phoenix.zhtml?c=202310\&p=irol-newsArticle \&ID=1249580

38. Pratt, C. B. (1993). Critique of the classical theory of situational ethics in U.S. public relations. Public Relations Review, 19(3), 219-234.

39. Recall of peanut butter products spreading. (2009). USA Today

40. Recalls \& alerts, (n.d.). Retrieved June 25, 2010 from http://www.foodsafety.gov/compliance/index.html.

41. Roman, K.D. \& Moore, M. A. (2010). A spreading crisis: Applying image restoration theory and utilitarian ethics to the 2009 peanut butter recall. The International Academy of Business and Public Administration Disciplines Fall 2010 Conference, New Orleans, LA.

42. Sellnow, T. L., Ulmer, R. R., \& Snider, M. (1998). The compatibility of corrective action in organizational crisis communication. Communication Quarterly, 46, 60-74.

43. Severson, K. (2009, February 4). Who's sticking with us? The New York Times, Retrieved September 20, 2009, from http://www.nytimes.com.

44. Schmit, E., \& Weise, E. (2009a, January 29). Peanut butter recall grows: Expanded to 2 years' worth of products. USA Today, p. 1B.

45. Schmit, E., \& Weise, E. (2009b, February 2). Peanut product recalls spread fast; Industry fears impact on sales of unaffected foods. USA Today, p. 1B. 
46. Siomkos, G. J. \& Malliaris, P. G. Consumer response to company communications during a product harm crisis. Journal of Applied Business Research (JABR). 6 (12) 1992, 1-59.

47. Smith, R. (2009, April 15). Peanut industry waiting for good news. Southeast Farm Press, p. 7.

48. Ulmer, R. R., Seeger, M.W., \& Sellnow, T. L. (2007). Post-crisis communication and renewal: Expanding the parameters of post-crisis discourse. Public Relations Review, 33(2), 130-134.

49. United States. Congress. Senate. Committee on agriculture, nutrition, and forestry. (2009). 111-Senate hearings: Examination of federal food safety oversight in the wake of peanut products recall, S. Hrg. 111231, February 5, 2009. DOCID: f:49576.wais.

50. Weise, E. (2009, April 2). Nuts. USA Today, p. 1B.

51. Weise, E. \& Schmit, J. (2009, January 22). Recall of peanut butter product spreading; Even pet treats among 125 items possibly tainted by salmonella. USA Today, p. 8D.

52. Wittenberger, K., \& Dohlman, E. (2010, February). Peanut outlook: Impacts of the 2008-09 foodborne illness outbreak linked to salmonella in peanuts, a report from the Economic Research Service of the USDA. Retrieved March 21, 2010, from http://www.ers.usda.gov/publications/ocs/2010/02Feb/ocs10A01/. 


\section{NOTES}

